\title{
Fake News: desinformación en la era de la sociedad de la información
}

\author{
Fake News: disinformation in the information society
}

Marián Alonso González, Universidad de Sevilla, Facultad de Comunicación, Avda. Américo Vespucio, s/n, despacho H2, 41092 Sevilla malonsog@us.es | Orcid: http://orcid.org/0000-0003-2676-0449

DOI: http://dx.doi.org/10.12795/Ambitos.2019.i45.03

\begin{abstract}
Resumen
Las nociones de verdad y mentira como valores del Periodismo se están viendo afectadas a consecuencia del impacto de las nuevas tecnologías, ya que establecen la instantaneidad como ritmo normal de la información y cualifican el rumor y las noticias no verificadas como un valor lógico de la misma.

A lo largo del presente estudio pretendemos analizar cómo las plataformas en línea y otros servicios de Internet han favorecido la proliferación de noticias que intencionadamente inducen a error, dando lugar a informaciones periodísticas que carecen de rigor y credibilidad y afectando a la percepción de la realidad por parte de la ciudadanía.

Partiendo de la premisa de que el flujo constante de información aleja al Periodismo del rigor informativo y la verificación, proponemos un estudio documental bibliográfico sobre las redes sociales, las nuevas aplicaciones móviles y la difusión viral de noticias falsas,
\end{abstract}


estudio que combinaremos con el análisis cualitativo no experimental a fin de evidenciar cómo la viralización que propician las redes sociales, y la mala praxis de algunos medios de comunicación al publicar informaciones sin contrastar, dejan en evidencia la credibilidad de los medios.

Para combatir la creciente tolerancia al engaño y la mentira se hace necesaria una apuesta real por la alfabetización mediática de los ciudadanos y por potenciar la labor del periodista profesional: ser testigo, descifrar e interpretar la realidad que nos rodea y garantizar una información cierta y conforme a los criterios de transparencia, precisión e imparcialidad.

\begin{abstract}
Notions of truth and lies as values of journalism are being affected as a result of the impact of new technologies, since they establish instantaneousness as a normal rhythm of information and qualify rumor and unverified news as a logical value of it.
\end{abstract}

The present study aims to analyze how online platforms and other Internet services have favored the proliferation of news that are intentionally misleading, giving rise to journalistic information that lacks rigor and credibility and affecting the perception of the reality on the part of the citizenry.

Starting from the premise that the constant flow of information keeps journalism from informative rigor and verification, we propose a bibliographic documentary study on social networks, new mobile applications and the viral dissemination of false news, a study that we will combine with qualitative analysis not experimental in order to show how the viralisation that social networks cause, and the malpractice of some media to publish information without contrast, leave evidence of the credibility of the media.

To combat the growing tolerance of deceit and lies, it is necessary to make a real bet for the media literacy of citizens and to enhance the professional journalist's work: to be a witness, to decipher and interpret the reality that surrounds us and to guarantee certain and accurate information to the criteria of transparency, precision and impartiality.

Palabras clave: Fake News, redes sociales, whatsApp, difusión viral, información

Keywords: Fake News, social networks, whatsApp, viral dissemination, information

\title{
1. INTRODUCCIÓN
}

Uno de los últimos bulos difundidos vía WhatsApp y redes sociales ha provocado que miles de franceses se hayan sumado a las protestas convocadas por los Gilets Jaunes (chalecos amarillos) en Francia. El motivo, una campaña de intoxicación sobre el Pacto de Marrakech, un Pacto Mundial para las migraciones seguras, ordenadas y reguladas, una declaración simbólica de Naciones Unidas que no impone ninguna obligación de acogida, pero que un bulo ha convertido en una imposición de la ONU que "prevé la llegada de 480 inmigrantes para destruir Europa". 
"Emigrantes llegando por miles", o hay que impedir que Macron firme porque "cuatro millones de emigrantes van a llegar a Francia" son algunas de las incendiarias consignas que circulan libremente por Internet y a las que algunos políticos han dado visos de veracidad. Es el caso de Lydia Guirous, de los Republicanos, quien acusaba en su Twitter a Macron de "traicionar a los franceses ratificando un pacto que amenaza nuestra soberanía y nuestra integridad. Cada pueblo tiene derecho a escoger a quién desea acoger" (Gil, 2018).

Las fake news o noticias falsas se han convertido en una constante dentro del Periodismo y en un verdadero problema a la hora de discernir la verisimilitud de una información, hasta el punto de que la consultora Gartner (2017) sostiene en su último informe de "Predicciones Tecnológicas para el 2018" que en el 2022 el público occidental consumirá más noticias falsas que verdaderas y que no habrá suficiente capacidad, ni material ni tecnológica, para eliminarlas.

Los bulos no son un fenómeno nuevo dentro del Periodismo, de hecho, en "las gacetas del siglo XVIII los bulos y libelos eran una herramienta de poder bien conocida por reyes y válidos, y en el siglo XX los totalitarismos se sirvieron de falsedades como herramienta de desinformación propagandística" (Fernández, 2014, p.20).

Sin embargo, gracias a Internet y las redes sociales el rumor cobra una dimensión nueva en la que entra en juego factores como "velocidad, amplitud y universalidad, vectores que potencian el auge de su difusión amparados en la participación, el anonimato, la fuente oculta y la dificultad para borrar su rastro" (Alonso y Orta, 2015).

Las nuevas tecnologías permiten que se potencie la distribución de las noticias falsas y que éstas, como afirma el diario La Tribuna (2018), se posesionen del espacio de las redes sociales, hasta el punto de "dominar la conversación con alto rédito para obtener el propósito que se ha dejado quien la difunde". Su poder es tan grande que, según un estudio realizado por la Asociación de Internautas (2018), el 70\% de los españoles no sabe distinguir entre una noticia verdadera y un rumor o un bulo, y "ello es debido a que no existe la fórmula exacta para diferenciar entre la información cierta y la que no lo es".

La libertad de expresión y de información, pilares básicos de nuestra democracia, deben encontrar un límite en el derecho a la veracidad de las informaciones que recibimos. El conocimiento de la realidad es lo que nos permite a los receptores formarnos opinión sobre el mundo que nos rodea, sin embargo, el flujo permanente de información y las noticias falsas erosionan esa credibilidad generando desinformación, entendida ésta como "cualquier contenido informativo falso que haya sido creado y difundido de forma deliberada" (Wardle, 2018).

Wardle, que denomina "desorden de información" a la desinformación, explica que ésta se produce a cuando nos referimos a noticias que no están verificadas, cuando 
compartimos información falsa para hacer daño, así como a la mala información que se construye para dañar de forma consciente a través de la información.

El auge desmedido de las noticias falsas en las redes sociales empezó con la elección de Donald Trump como presidente de los Estados Unidos pero tiene visos de alargarse mucho más que su mandato (Jané, 2017). Durante la carrera electoral entre Trump y Hillary Clinton, la mentira distribuida masivamente por Internet se convirtió en una normalidad, y lo que es más grave, en un "arma muy potente de propaganda" (Journell, 2017).

Hoy día, la búsqueda en Google del término fake news arroja un resultado de 836 millones de entradas y evidencia su magnitud, hasta el punto de llegar a ser elegida "Palabra del año 2017" por el diccionario Collins y candidata a igual honor de la Fundéu BBVA. Ante este panorama, se hace necesario que los guardianes de la verdad controlen los canales de producción y distribución de la información, al tiempo que los periodistas, como mediadores de la realidad circundante, deben encargarse de discernir qué información es relevante, así como investigar y verificar su exactitud.

La verificación de la información es uno de los pilares sobre los que se sustenta la profesión periodística y es, especialmente, en estos tiempos inciertos de crisis cuando cobra especialmente sentido porque, como señalan Kovach y Rosentiel (2003), la probabilidad de que haya más mentiras se incrementa y, por este motivo, la prensa más que añadir contexto e interpretación necesita concentrarse en la síntesis y la verificación.

En esta misma línea se pronuncian López-Burrul et al. (2018) quienes determinan que el reto de los periodistas es doble, por una parte, especificar el grado de confianza de una fuente de información y, por el otro, combatir la viralización de la información falsa.

\subsection{Redes sociales e información}

Las nuevas tecnologías de la información han favorecido la democratización informativa, sin embargo, este proceso comunicativo bidireccional por el cual los ciudadanos se pueden convertir en el origen de las noticias se encuentra exento de controles de veracidad, por lo que desaparece el rigor informativo y la verificación de datos, cualidades intrínsecas del Periodismo.

Las redes sociales han diseñado un panorama informativo descentralizado que afecta de forma importante a la producción de información. Las noticias creadas por periodistas conviven con las producidas por cualquier usuario (Van-Dijck, 2009; Flichy, 2010), generándose un espacio de superabundancia informativa (Keane, 2013) que unido al anonimato que favorecen las plataformas digitales genera el caldo de cultivo idóneo para la proliferación de noticias falsas. 
Además, como recoge Casero Ripollés (2018), citando a Manovich (2011), la facilidad de producción que poseen las redes sociales provoca que el contenido que circula a través de ellas pueda ser manipulado para ensamblar, añadir o remover información, abriéndose paso con ello a procesos de re-encuadre, de reasignación de sentido o de recontextualización de la información que pueden alterar su significado.

Cada minuto, afirman Torres y Lorenzo (2018), "se realizan más de 3,5 millones de búsquedas en Google, se producen 900.000 accesos a Facebook y se envían 156 millones de emails". Sin embargo, una mayor cantidad de información no significa que exista más calidad, como evidencia el hecho de que esta eclosión informativa ha provocado que durante 2017 se detectaran 122 páginas webs dedicadas a publicar noticias falsas.

La proliferación de plataformas noticiosas digitales también ha modificado la manera en la que accedemos a la información. Mientras que los medios tradicionales han ido perdiendo audiencia entre las generaciones más jóvenes, las redes sociales han pasado a ser hegemónicas.

Un reciente estudio realizado por Pew Research Center (2018) demuestra que las redes sociales se sitúan por encima de la prensa escrita como medio para acceder a las noticias de actualidad entre los adultos estadounidenses, de manera que el $20 \%$ prefiere informarse por redes sociales como Facebook o Twitter, que por los periódicos (16\%).

En España, el consumo de Internet por parte de los jóvenes menores de 35 años ha superado incluso al de televisión, como puede apreciarse en el siguiente gráfico (Ver Gráfico1).

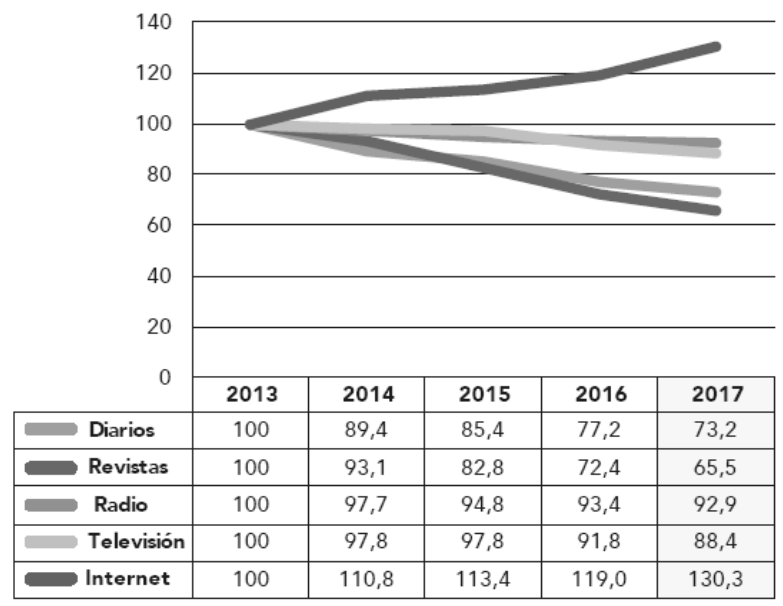

Gráfico 1. Consumo de medios, por tiempo (2013-2017)

Fuente: Informe Anual de la Profesión Periodística (2018) 
Además, el uso de las redes sociales y de mensajería como fuente informativa llega al $77 \%$, según el informe Anual de la Profesión Periodística (2018); un 15\% más que la media europea (Ver Gráfico 2).

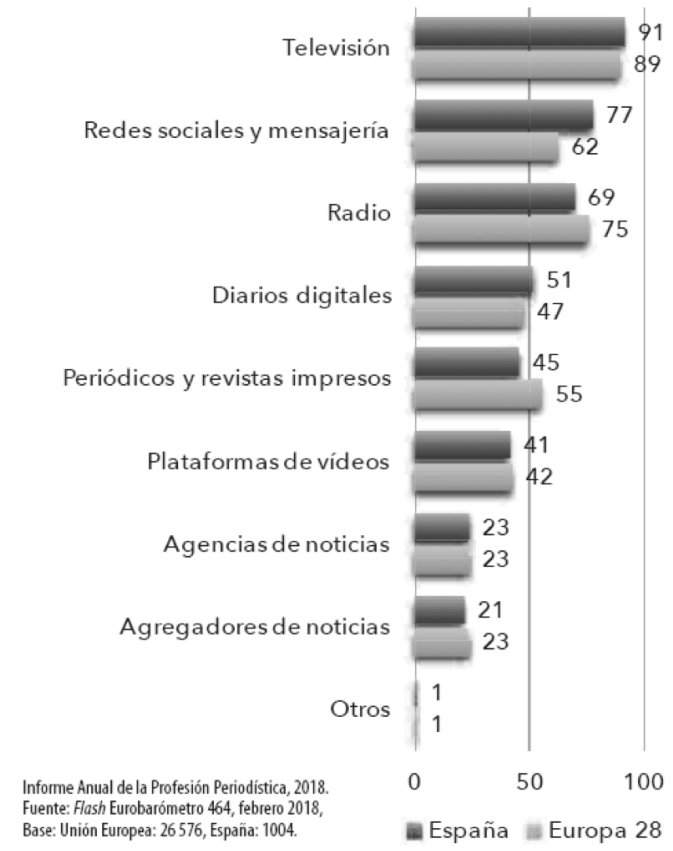

Gráfico 2. Uso de los medios para informarse

Fuente: Informe Anual de la Profesión Periodística (2018)

Las redes sociales "posibilitan un descubrimiento casual de las noticias que provoca que los usuarios no tienen que ser buscadores activos para estar expuestos a las noticias" (Casero Ripollés, 2018, p.968), lo cual contrasta con el modelo tradicional por el cual es el receptor quien, de forma intencionada, acude a buscar la información. En este sentido, indica Castells (2009) que las redes sociales han introducido el concepto de autodistribución, el cual implica que son los propios usuarios quienes deciden a través de qué canales inician la difusión de un contenido.

Además, el que las redes sociales se conviertan en fuente de información ha provocado que hechos incuestionables pierdan la batalla frente a hechos alternativos y las emociones. Este planteamiento de la posverdad de McIntyre (2018) parte de la base de que todos los seres humanos nos sentimos influidos por nuestros sesgos cognitivos, de forma, que a la hora de creer algo siempre entran en juego variables ideológicas como son nuestros sentimientos, opiniones y motivaciones, los cuales influyen en la forma en la que construimos nuestra realidad.

Gracias al uso de las redes sociales como fuentes de información estamos contribuyendo a la deconstrucción informativa ya que se atenta contra los conceptos de 
verdad y objetividad. La fragmentación de los medios y la omnipresencia de las redes han favorecido que la audiencia se encierre en sus particulares universos informativos en base a su ideología preferida, afirma Mclntyre, al tiempo que esos medios alternativos de comunicación han sabido aprovecharlo desinformando y fabricando noticias únicamente con el objetivo de ganar audiencia o favorecer su agenda ideológica.

De forma paralela, los medios de comunicación han instaurado un modelo de información continua que obliga a los profesionales a generar y difundir noticias de manera permanente. Las redacciones se encuentran sometidas a una doble presión: ser las primeras en difundir una noticia y publicarla con toda la corrección y cuidado de una edición escrita (Torres, 2007).

Es por todo ello que los medios de comunicación "han llegado a depender en ciertos aspectos de los nuevos medios" (Owen, 2018). Los menores ingresos publicitarios, los recortes en las redacciones de los periódicos y la desaparición de las unidades de investigación han provocado que:

Los periodistas convencionales han acabado confiando en los contenidos que surgen en los nuevos medios como fuentes de noticias. Estas tendencias han influido seriamente en la calidad y la naturaleza de los contenidos de las noticias, además de en el estilo del periodismo político, que ha quedado más impregnado de «infoentretenimiento» y de citas de canales de Twitter (Owen, 2018).

La confluencia de ambos factores ha originado un entorno comunicativo complejo en el que coexisten y conviven los medios tradicionales con nuevas plataformas digitales, lo cual conduce a una fragmentación de la audiencia y a un aumento de las posibilidades de elección, pero también a que los periodistas dejen de ser los únicos gatekeepers de la información, abriendo la puerta a la rápida y masiva distribución de contenidos no contrastados (Van-Aelst et al., 2017).

\section{OBJETIVOS Y METODOLOGÍA}

A lo largo del presente estudio nos marcamos como objetivo principal analizar cómo las plataformas en línea, las redes sociales y otros servicios de Internet han favorecido la proliferación de noticias que intencionadamente inducen a error, dando lugar a informaciones periodísticas que carecen de rigor y credibilidad. De manera complementaria, y como objetivo secundario, nos proponemos, además, identificar las medidas que se están poniendo en marcha para corregir esta tendencia.

Para abordar dichos objetivos, proponemos un estudio documental bibliográfico sobre las redes sociales, las nuevas aplicaciones móviles y la difusión viral de las noticias falsas, estudio que combinaremos con la observación participante, entendida ésta como 
la mirada activa que faculta al investigador a aprender acerca de una actividad en el escenario natural donde se desarrolla (Kawulich, 2005) y el análisis cualitativo no experimental, a fin de evidenciar cómo la viralización que propician las redes sociales y la mala praxis informativa deja en evidencia la credibilidad de los medios.

Para ello, hemos realizado un seguimiento pormenorizado de las informaciones que sobre noticias falsas han sido publicadas en los diarios El Mundo y El País, por ser los que un mayor número de lectores poseen según datos del último EGM (2018), durante los meses comprendidos entre mayo y diciembre de 2018, por considerar que se trata de un periodo más que suficiente para el desarrollo de esta investigación, y con objeto de otorgar la mayor actualidad posible a la misma.

De forma complementaria, durante el mismo periodo hemos realizado un seguimiento de las noticias publicadas en las redes sociales Facebook y Twitter, así como de las difundidas mediante la aplicación de mensajería instantánea WhatsApp, a fin de poder detectar las posibles noticias falsas que han circulado durante esos siete meses.

En esta labor nos han sido de gran ayuda las webs de verificación informativa Maldito Bulo, $B$ de Bulo y Newtral, ya que estas plataformas contribuyen desde el rigor y la credibilidad a desmentir las noticias falsas que circulan por Internet. También con este objetivo hemos procedido a estudiar la herramienta de Fast-check implementada por Google y el proyecto internacional de verificación The Trust Proyect, que exige el cumplimiento de unos estándares básicos a fin de que las noticias cumplan unos criterios mínimos de credibilidad y fidelidad.

Por último, hemos analizado el funcionamiento de portales de noticias falsas como El Mundo Today y Hay Noticia, por ser los más conocidos y los que habitualmente consiguen viralizar más informaciones inciertas y con un toque de humor.

\section{RESULTADOS}

La incorporación de los usuarios a la distribución, unida a la arquitectura digital de las redes sociales, ha provocado cambios en la forma de circulación de la información en el entorno digital, dice Casero Ripollés (2018) y, en este sentido, señala que "re-tuiteando un mensaje, compartiendo un contenido o pulsando el botón 'me gusta', los usuarios contribuyen a ampliar la circulación de los contenidos y a atribuirle relevancia ante otros".

Un claro ejemplo lo encontramos el pasado 18 de octubre cuando el medio catalán catalunyapress.cat publicó que el líder de Ciudadanos, Albert Rivera, se había saltado un control de antiexplosivos en el aeropuerto de El Prat (Ver Imagen 1). 


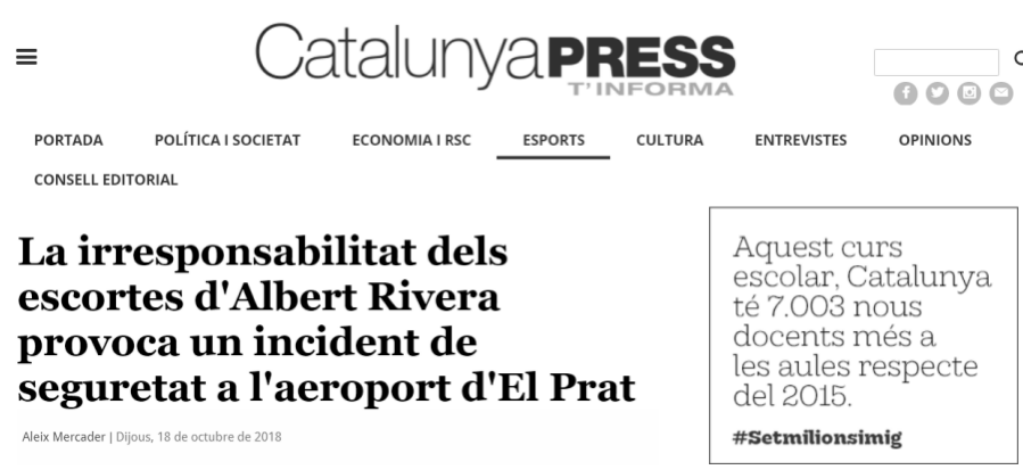

Imagen 1. Información publicada por Catalunyapress

Fuente: Catalunyapress

En días sucesivos, diversos medios se hicieron eco de esta información inicial añadiendo nuevos detalles erróneos, como que también era un control antidroga. El punto álgido de esta información falsa se alcanzó cuando el secretario de Organización de Podemos, Pablo Echenique, dio por ciertas las noticias publicadas, llegando a afirmar que Rivera "quiere (y consigue) saltarse un control antidrogas" (Ver Imagen 2), según recoge Guisado (2018), pese a que esta información ya había sido desmentida en las redes sociales por Maldito Bulo.

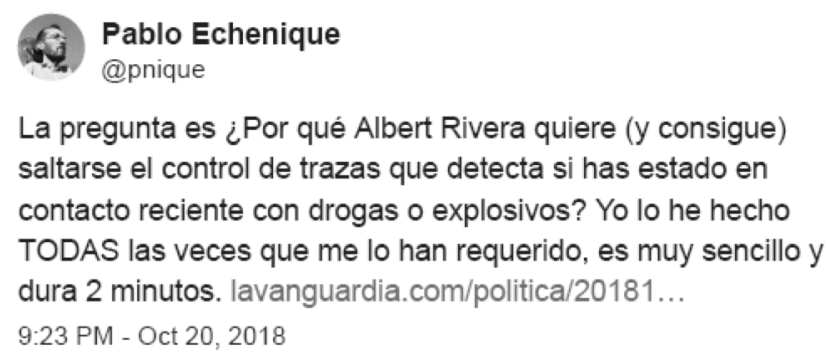

Imagen 2. Tuit publicado por Pablo Echenique Fuente: Twitter

\subsection{Mentiras y redes sociales}

Un reciente estudio realizado por Vosoughi, Roy y Aral (2018), y publicado en la revista Science, afirma que la información falsa se extiende hasta seis veces más rápido que la verdad. De hecho, una noticia falsa tiene un $70 \%$ más de probabilidades de ser retuiteada que una historia real, y este fenómeno se produce en base a dos mecanismos convergentes: el efecto cascada y la polarización de grupos.

Según Carl Sunstein (2009), ambos factores provocan que la señal se refuerce cuanta más gente la recibe, hasta llegar a un punto en que es casi imposible resistirse a ella; al 
tiempo que se produce una asimilación tendenciosa, es decir, nuestras opiniones se fortalecen cuando las compartimos con personas afines y éstas nos las corroboran, pero también cuando las discutimos con quienes discrepamos afianzándonos de nuevo en su error y en nuestro acierto.

Este mecanismo de circulación de información, propio del entorno digital, convive con la difusión vertical practicada por los medios tradicionales, lo que provoca importantes repercusiones sobre los contenidos que llegan a la audiencia, de forma que "los efectos de la mediación inducida por los medios sociales provocan que las plataformas sociales no sean una fuente de datos ideal para los ciudadanos que buscan una información claramente estructurada" (Stier et al., 2018, p.68).

\subsubsection{Facebook y Twitter}

La arquitectura de cada plataforma digital es distinta (Nahon, 2016) y, por ello, cada una tiene sus propias características diferenciales. Así, Facebook y Twitter convierten a los ciudadanos en lo que Cremades (2007) denomina "nodos de red", pues a través de su interacción configuran conexiones consideradas de alto clustering, ya que son redes densamente conectadas a nivel local, lo cual influye de forma proporcional en el proceso de transmisión de la información.

Esta hiperactividad comunicativa "basada en un exceso de contenidos que genera ruido" (Palomo y Sedano, 2018, p. 1385), permite que se cuelen rumores y surjan noticias falsas, al tiempo que debido a su "estructura de comunidad y a su carácter asortativo" (Buldú, 2011), la difusión de noticias adquiere un estatus viral, hasta el punto de que sea irrelevante quién inicia el proceso de difusión, ya que la ausencia de propagadores influyentes es precisamente lo que le otorga una mayor fuerza de difusión.

Para hacer frente a este contexto de inseguridad informativa, Facebook ha puesto en marcha un programa para detectar informaciones falsas. La compañía ha lanzado un sistema de avisos, similar al Fast Check de Google, para indicar a los usuarios si una noticia es falsa o no, al tiempo que ha creado un equipo exclusivo.

En colaboración con portales como Snopes y Politifact, Facebook rastrea todo lo que sucede en la red social para que no se vuelva a repetir el escándalo de las informaciones falsas publicadas y que generaron gran debate sobre la victoria electoral de Donald Trump. Además, la red social ha decidido formar a periodistas y usuarios y aplicar una serie de filtros que permiten marcar una noticia en el timeline como "falsa".

Según Alonso (2017), esa noticia irá a un borrador y será verificada por fact-checkers profesionales, de forma que cuando alguien intente compartirla aparecerá un mensaje que avisa que la historia ha sido cuestionada por al menos dos organizaciones, si el usuario insiste en compartirla la plataforma le preguntará si está seguro y, si aun así,

Ámbitos. Revista Internacional de Comunicación | ISSN: 1139-1979 | E-ISSN: 1988-5733, №. 45. (2019) 
decide a publicarla en su perfil la publicación aparecerá con la marca "cuestionada" para que sus contactos puedan verlo" (Ver Imagen 3).

En España esta herramienta se implementó en septiembre de 2017 gracias a la iniciativa de Alemania, auténtico motor a la hora de forzar cambios en esta red social dentro de la Unión Europea.

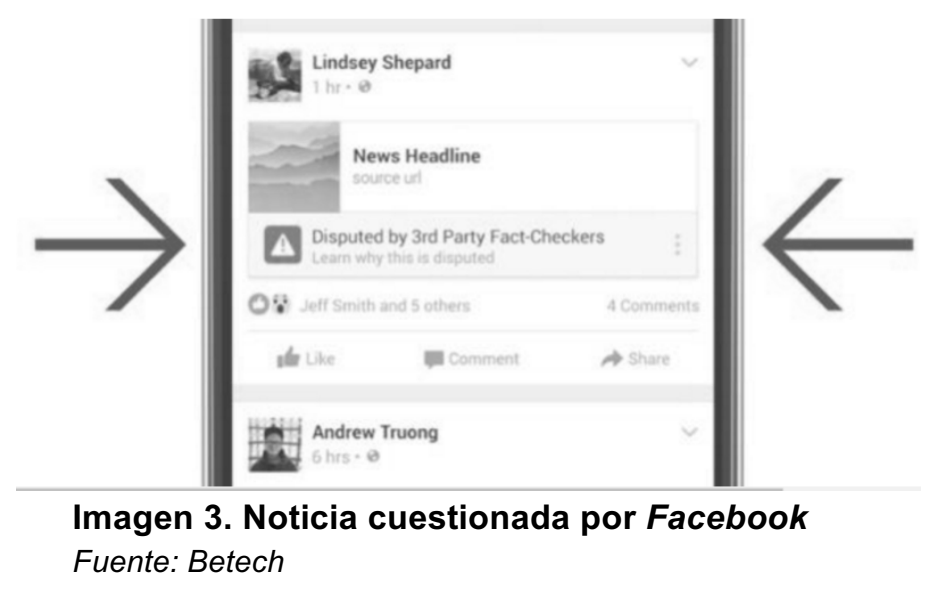

Para facilitar la labor de verificación de los usuarios, Facebook ha publicado un decálogo que invita a los usuarios a dudar de los títulos llamativos escritos con mayúsculas y signos de exclamación, observar con atención la URL, asegurarse de que la noticia está escrita por una fuente de confianza, detectar si el formato es poco común, presenta errores ortográficos, diseños extraños o si las imágenes y vídeos parecen manipulados; comprobar las fechas, verificar las pruebas aportadas por el autor y consultar si cualquier otro medio ha publicado una noticia similar, entre otros aspectos.

La desinformación también se ha convertido en una lacra a erradicar en Twitter. Durante las presidenciales americanas "la red social publicó más de 6,6 millones de tuits que incluían o enlazaban a noticias falsas, montajes o conspiraciones en el mes previo a las elecciones" (Monfort, 2018).

Un reciente estudio publicado por Knight Foundation (2018), sobre un total de 10 millones de tuits de 700.000 cuentas distintas, defiende que la red social del pajarito publica más de un millón de tuits falsos al día, al tiempo que destaca el inmovilismo de la compañía a este respecto y que la mayoría de las cuentas centradas en extender noticias falsas son bots o cuentas semiautomatizadas.

Las noticias falsas se viralizan entre 10 y 20 veces más rápido que los hechos. Una afirmación que se sustenta en el estudio llevado a cabo por Vosoughi, Roy y Aral (2018), quienes analizaron 126.000 noticias publicadas en Twitter, las cuales fueron tuiteadas 
de forma acumulativa 4,5 millones de veces por, aproximadamente, 3 millones de personas entre 2006 y 2017.

El origen de esta investigación reside en los atentados de Boston de 2013 y en la cantidad de noticias falsas que se publicaron en torno a ellos. Para determinar si las historias eran verdaderas o falsas, el equipo utilizó las evaluaciones de seis organizaciones de verificación de hechos (factcheck.org, hoax-slayer.com, politifact.com, snopes.org, truthorfiction.com y urbanlegends.about.com) y comprobaron que sus juicios se superponían en más del $95 \%$ de las ocasiones.

Entre sus conclusiones, Vosoughi, Roy y Aral (2018) apuntan a que la facilidad de propagación de las noticias falsas reside en la propia psicología humana, las noticias falsas son más novedosas y la gente quiere ser la primera en compartir informaciones.

Para hacer frente a la proliferación de noticias falsas, Twitter ha eliminado casi 70 millones de cuentas entre los meses de mayo y junio de 2018, al tiempo que ha introducido actualizaciones y la supervisión activa de los contenidos.

No obstante, la medida no está dando los resultados esperados y aún son muchas las noticias que escapan a sus controles de calidad, de hecho, con motivo del asesinato de Laura Luelmo y en medio del debate sobre la prisión permanente revisable, comenzó a circular el bulo de que el asesino de Marta del Castillo, Miguel Carcaño, saldría de prisión en unos días. Instituciones Penitenciarias tuvo que salir a desmentir la noticia.

Otro ejemplo lo encontramos en un burdo montaje que ha circulado durante el mes de diciembre en Twitter y donde se puede ver a Santiago Abascal, número uno de VOX, besando el mármol de la tumba de Franco en el Valle de los Caídos (Ver Imagen 4).

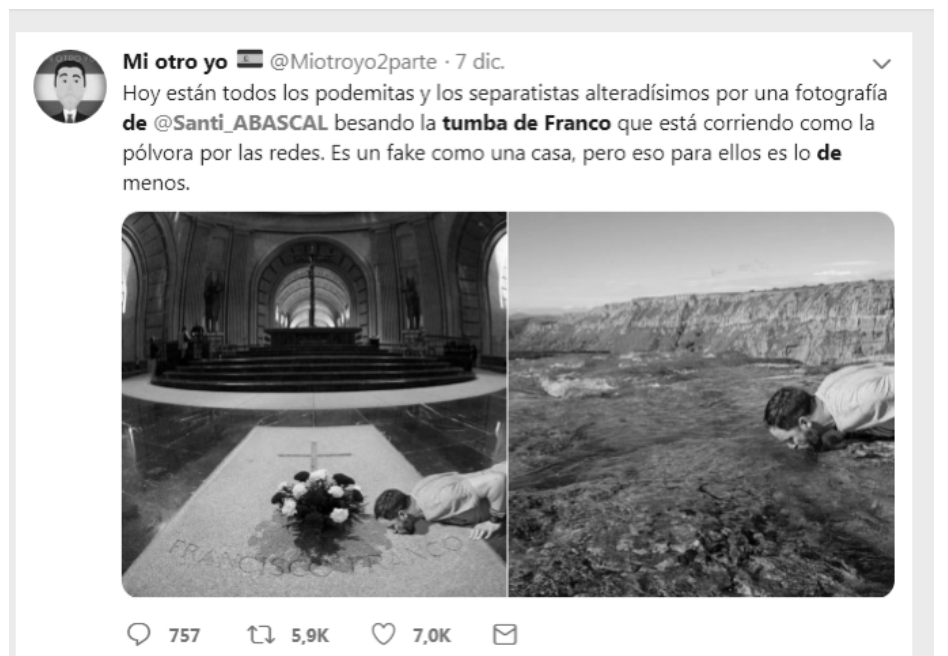

Imagen 4. Montaje de Santiago Abascal que ha circulado por Twitter Fuente: Twitter 
Con objeto de apostar por la transparencia, Twitter ha anunciado la puesta en marcha de una nueva herramienta (Transparency Center) que permitirá realizar seguimientos sobre quiénes han sido los usuarios que han recibido impactos de alguna campaña, al tiempo que incluirá informes sobre quién se publicita en esta red social, por cuánto tiempo y cuáles son los contenidos de los anuncios.

\subsubsection{WhatsApp}

El Digital News Report (Newman, 2018), elaborado anualmente por el Instituto Reuters de la Universidad de Oxford, asegura que el uso de WhatsApp para el consumo de información se ha duplicado en los últimos cuatro años, coincidiendo con la crisis de Facebook y el desplome de la prensa.

La aplicación de mensajería instantánea más popular del mundo, con más de 1.500 millones de usuarios en 180 países y que ha triplicado desde 2014 su uso informativo (un tercio de los españoles utiliza la aplicación como principal fuente de información), también se ha convertido en un nuevo canal para la proliferación de las noticias falsas.

Su comportamiento no es diferente al de "las cadenas de correos electrónicos de hace una década" (El Mundo, 2018), sin embargo, su potencial peligro reside en el título personal de los mensajes, pues es otra persona quien los comparte y el hecho de que provenga de uno de nuestros contactos genera que la noticia falsa alcance un mayor grado de credibilidad.

WhatsApp permite llegar a los teléfonos móviles en una plataforma de amplísima difusión, prácticamente del 100\%, con unos niveles de descentralización extraordinariamente difíciles de controlar, afirma Gutiérrez-Rubi (2015), es por ello que, "detectar noticias falsas en esta plataforma es particularmente difícil ya que las conversaciones, personales o de grupo, están encriptadas y son privadas" (Tardaguila, 2018).

Desde finales de mayo de 2018, 14 personas han sido víctimas mortales de linchamientos en India, debido a mensajes y vídeos compartidos en las redes sociales. Esta ausencia de educación digital también ha provocado problemas en Colombia, donde un joven de 23 años fue asesinado en noviembre por una turba descontrolada a raíz de una versión falsa que circulaba por WhatsApp sobre el secuestro de un niño.

Un caso similar se produjo también en México, donde una falsa información provocó que una multitud se agolpara frente a la comisaría para linchar a dos hombres, detenidos por alteración del orden, convencidos de que en realidad eran secuestradores de menores. 
La noticia de su arresto se difundió rápidamente, gracias a un residente del pueblo que comenzó a transmitir en directo por Facebook imágenes de lo que sucedía ante la comisaría, al tiempo que otro residente usaba un altavoz para organizar una colecta ciudadana y comprar combustible para quemar a los detenidos (Martínez, 2018).

La convocatoria reunió a una multitud que forzó la reja de la comisaría, sacó a los detenidos, los golpeó salvajemente y los quemó vivos con gasolina (Ver Imagen 5).

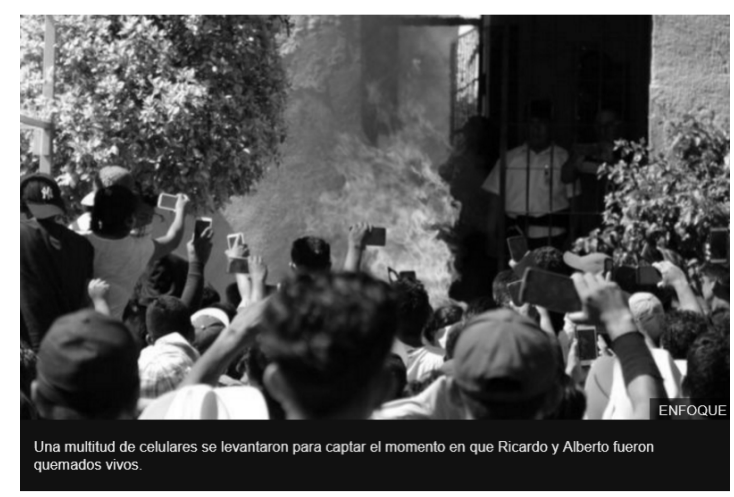

Imagen 5. Multitud grabando el linchamiento de México

Fuente: Enfoque (BBC)

En España los bulos también son bastante frecuentes. La mayoría suelen presentar unas pautas comunes que los estructuran y los hacen reconocibles y que, según la community manager de la Policía Nacional pueden resumirse en: son anónimos, hacen referencia a una fuente de confianza, están redactados de forma atemporal y en castellano neutro a fin de favorecer su difusión en países de habla hispana, y suelen tener un gancho (miedo, morbo, etc.) que incita a la petición de reenvío para alertar o concienciar a otras personas.

Uno de los más frecuentes es el de la supuesta versión Gold y Martinelli de la aplicación de WhatsApp que, según su texto, es una versión mejorada de la aplicación con características y ventajas exclusivas de la aplicación pero que, en realidad, no es más un caballo de Troya a través del cual un virus intenta robar información del móvil del usuario.

Para desactivar sus efectos, es habitual que Policía, Guardia Civil y asociaciones de consumidores denuncien su existencia a través de este mismo canal (Ver Imagen 6), y, en esta lucha, también los ciudadanos "han adquirido un nuevo rol activo para ayudar a los medios a reducir la desinformación y avisar de la circulación de noticias falsas" (Palomo y Sedano, 2018, p.1396). 


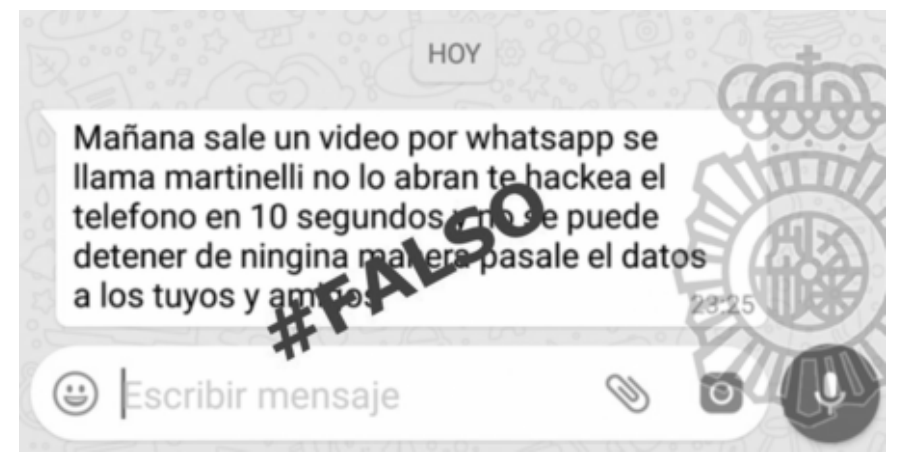

Imagen 6. WhatsApp de la Policía Nacional alertando de un bulo

Fuente: WhatsApp

Por su parte, la plataforma de mensajería, en una clara apuesta para luchar contra las noticias falsas, ha limitado a cinco el número de veces que se puede reenviar un mensaje, una de las funciones más utilizadas de la aplicación.

\subsection{Portales de noticias falsas}

El concepto de noticia falsa puede llegar a ser polisémico, es decir, abarca desde aquellas informaciones que todo el mundo sabe que es mentira, hasta aquellas publicadas con datos falsos y que se han saltado los controles de calidad de un determinado medio de comunicación.

Según Rochlin (2017), una noticia falsa se puede definir como un titular y una historia deliberadamente falsa publicada en una web que quiere parecer un sitio de noticias reales. En los últimos años han proliferado los portales de noticias falsas, que se caracterizan por emitir informaciones inconcebibles.

El caso más conocido es El Mundo Today, una página de humor cuyo contenido es pura ficción con objeto de arrancar más de una risa, pero cuyo estilo "ha sentado un precedente para que otros copien su estilo y rebasen la barrera de lo cómico en busca de idear falsas noticias que se hagan virales" (Sedano, 2018).

A pesar de que reconoce abiertamente publicar noticias ficticias (Ver Imagen 7), muchos medios de comunicación se han hecho eco de las mismas, dando por buenas informaciones inverosímiles. 


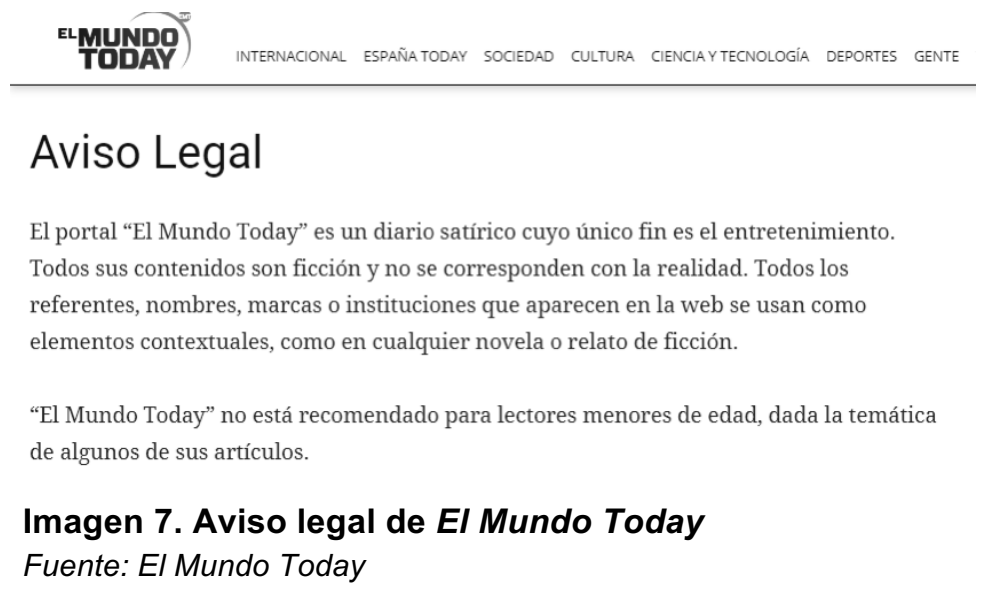

Así, en 2014, "Noticias Cuatro" publicaba en su web un artículo (copiado y pegado) de El Mundo Today sin citar la fuente y sin corroborar su contenido. Según Bravo (2014), bajo el titular "Los nuevos modelos de iPod no tendrán música de mierda", Cuatro mantuvo la noticia en su web 11 horas, cuando retiraron el artículo el texto desapareció sin dejar rastro ni rectificación alguna.

También la web Hay Noticia, dedicada a crear fake news humorísticas, ha logrado viralizar algunas de sus piezas. Es el caso de "Mujer lleva 28 años haciéndose pasar por ciega para no saludar a la gente", que ha sido traducida a 14 idiomas diferentes y se ha llegado a publicar en 24 países, lo cual ha provocado que numerosos portales internacionales hayan tenido que desmentir la noticia (Ver Imagen 8).

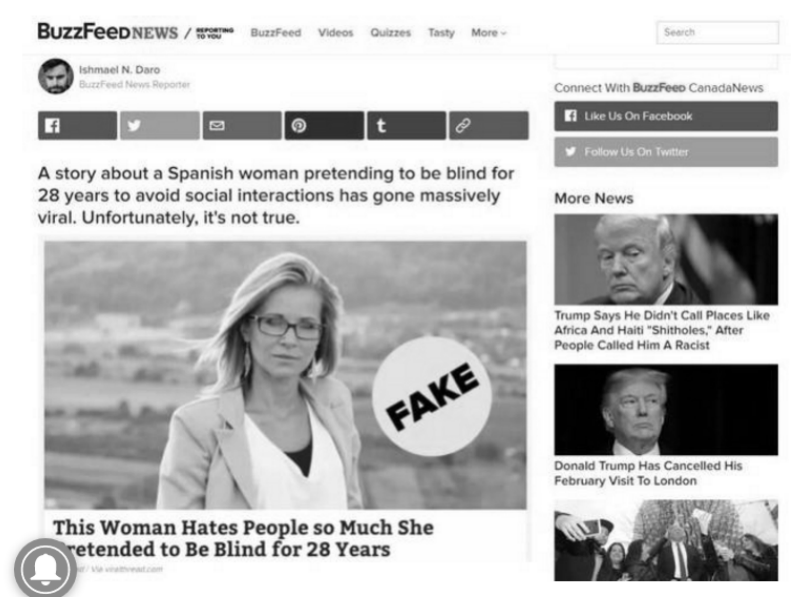

Imagen 8. El portal BuzzFeedNews desmintiendo la noticia

Fuente: BuzzFeedNews 
Elaborar noticias falsas nunca había sido tan lucrativo. Cuando un bulo se viraliza los nuevos tabloides digitales se hacen de oro gracias a las plataformas de publicidad automática de Google y otras compañías menores como TAboola, OpenX o SunMedia (Peinado y Muela, 2018).

Un experto en este tipo de prácticas es la web Digital Sevilla, uno de los diarios online líderes de la provincia de Sevilla (comScore, 2018) que ha logrado de promedio 160.000 usuarios únicos en España en los últimos doce meses y que según Peinado y Muela (2018), "no presenta diferencias respecto a una web de periodismo sometido a los controles de rigor tradicionales". Su éxito reside en titulares "llamativos, incluso irrespetuoso y faltón" (Fernández, 2018), ya que el objetivo es atraer la atención de la gente, lo cual les reportará un gran número de clics $\mathrm{y}$, por ende, un mayor beneficio económico.

Fuera de nuestras fronteras, otros diarios online se caracterizan por publicar noticias falsas. Tal es el caso de The Onion (EEUU), The Shovel (Australia), Waterford Wishpers News (Irlanda), The Lapine (Canadá), The Daily Mash (Reino Unido), Le Gorafi (Francia), Der Postillon (Alemania) o la publicación india Faking News, que deja muy clara la intención del diario.

En otras ocasiones, las noticias falsas proceden de los propios periodistas, quienes engañan a sus empresas y, por ende, a la audiencia. El último caso conocido ha sido el del periodista alemán Claas Relotius, ganador, entre otros, del premio al Periodista del Año 2014 de la CNN. Relotius ha admitido haber inventado datos y testimonios en al menos 14 de sus informaciones publicadas en la revista Der Spiegel.

Considerado un ídolo periodístico de su generación, el periodista no ha dudado en falsificar historias e inventar personajes, escribía sus textos basándose en hechos e informaciones de otros medios, imágenes de vídeos o publicaciones de las redes sociales, al tiempo que se inventaba las biografías de personajes reales o les citaba diciendo cosas que nunca habían dicho.

\subsection{Acabar con los bulos}

Para luchar contra las fake news y los bulos cualquier sistema es bueno y son muchas las iniciativas que se están desarrollando en este sentido. Así, Google ha desarrollado un método de etiquetado denominado "Fact Check" que permite cotejar fragmentos de texto con las publicaciones presentes en su catálogo de búsquedas, ha establecido acuerdos con compañías de verificación para luchar contra los bulos y ha mejorado el sistema de filtrado de resultados que realiza su algoritmo.

También el Departamento de Inteligencia Artificial del MIT y el Instituto de Investigación Informática de Qatar han diseñado un sistema automático que permite detectar noticias 
falsas y su fuente. El programa, que de momento sólo alcanza el $65 \%$ de fiabilidad y es capaz de deducir automáticamente el sesgo político de una noticia en el $70 \%$ de los casos, se basa en la comprobación de los datos, la recurrencia y la procedencia de las informaciones y asigna relevancia tanto al medio como a la información (Jané, 2018).

Otras iniciativas pasan por la puesta en marcha de varias plataformas dedicadas a detectar las informaciones falsas. Inspiradas en las veteranas Snopes o PolitiFact (EEUU), en cuestión de un año en España nacieron tres: Maldito Bulo en noviembre de 2016, El tragabulos en enero de 2017 y B de Bulo en marzo de 2017.

Maldito Bulo forma parte de Maldita.es, un proyecto periodístico independiente y sin ánimo de lucro cuyo fin es dotar a los ciudadanos de herramientas para discernir entre las noticias falsas y las verdaderas, para ello, monitorizan el discurso político y las informaciones que circulan en las redes y analizan el mensaje aplicando técnicas del periodismo de datos para su verificación.

Por su parte, $B$ de Bulo representa un modelo especial porque:

Tiene un teléfono móvil para recibir mensajes de la audiencia a través de WhatsApp sobre aquellos contenidos que desean saber si son verdaderos 0 falsos. Muchos mensajes falsos se transforman en contenido viral que circula a través de WhatsApp, y esta sección selecciona los contenidos falsos que la audiencia podría recibir, los analiza y recurre a diferentes fuentes para explicar el por qué el mensaje es un engaño, ofreciendo un servicio útil al ciudadano (Palomo y Sedano, 2018, p. 1387).

En esta misma línea, en enero de 2018 la periodista Ana Pastor puso en marcha Newtral, una compañía de contenido visual que, entre otras áreas de negocio, está orientada a la verificación de noticias y la innovación en el periodismo a través del factchecking de hechos. En realidad, Newtral/El Objetivo lleva desde 2013 realizando verificación de contenidos a través del programa "El Objetivo" de La Sexta y "ha sido el primer medio español en formar parte de la International Fact-Checking Network, la red internacional de verificadores independientes" (El Plural, 2019).

Tras 5 años verificando informaciones, Newtral se ha incorporado en marzo de 2019 al programa de verificación de datos externos de Facebook, al tiempo que invita a sus más de 80.000 seguidores en Twitter (@Newtral) a enviar a un número de WhatsApp las afirmaciones que escuchamos y sobre las que tenemos dudas que sean ciertas.

También con objeto de garantizar los estándares de confianza en las noticias publicadas, el consorcio internacional de medios de comunicación ha puesto en marcha The Trust Project que trabaja con plataformas tecnológicas, como el buscador Bing, a 
fin de reafimar el compromiso del periodismo con la transparencia, la precisión, la inclusión y la imparcialidad.

The Trust Project funciona como un indicador de veracidad que amplía la información contextual de las noticias, de manera que se puede saber quién ha publicado un artículo, qué citas y referencias incorpora y cuáles son los estándares éticos en los que se sustenta.

Sus principios son una adaptación de los presentados por la Comisión Hutchins en 1947 en relación con la prensa libre y socialmente responsable, y supone un compromiso en la equidad y exactitud, explicación de la misión, fuentes de financiación y la organización que respalda a los medios, acceso a los métodos de obtención de la información, así como garantizar la diversidad de voces y perspectivas, entre otros.

El proyecto cuenta con la participación de 121 medios de comunicación de todo el mundo, entre los que se encuentran los diarios españoles El País y El Mundo, y exige el cumplimiento de 8 estándares básicos que ayudan al lector a saber de qué debe fiarse, aumentando la credibilidad, fidelidad y posibilidad de que el usuario quiera pagar por lo que está leyendo, y que son:

- Mejores prácticas. Principios del medio, misión y fuente de financiación. Implica, además, la inclusión del código ético, el compromiso por la diversidad, el rigor, las correcciones y otros estándares.

- Información sobre el autor, trayectoria y artículos publicados.

- Tipo de trabajo: Identificación del género periodístico y etiquetado que distinga los textos de opinión, análisis o publicitarios de las noticias.

- Citas y referencias: Identificación de fuentes y, en caso de periodismo de investigación, acceso a las fuentes detrás de los hechos y las afirmaciones.

- Métodos de trabajo: Por qué los reporteros decidieron seguir una historia y cómo abordaron el proceso.

- Identificar cuándo la historia surgió en un lugar sobre el que el medio cuenta con un profundo conocimiento sobre el contexto local o de la comunidad a la que se dirige.

- Apuesta por las perspectivas diversas.

- Facilitar espacios para fomentar la participación de los lectores. 


\section{CONCLUSIONES}

Las transformaciones en la producción y distribución de la información que han introducido las nuevas tecnologías, en especial las redes sociales, han provocado una gran eclosión de fuentes informativas y que el flujo comunicativo sea constante, lo cual ha originado que los medios de comunicación dejen de ser la fuente primaria de las noticias y que se pierda parte del valor añadido que el periodista imprime a sus informaciones: la verificación y contextualización de las mismas.

A todo ello, hay que sumar el hecho de que las redes sociales no son artefactos neutrales, sino que su arquitectura digital está integrada por protocolos técnicos que permiten, constriñen e influencian el comportamiento de los usuarios, generando unas u otras prácticas comunicativas (Bossetta, 2018), un rasgo que obliga al desarrollo de mecanismos para verificar todos los contenidos que se reciben mediante las herramientas derivadas de la Web 2.0 .

Las noticias falsas y los debates sobre la posverdad son algunos de los retos a los que se enfrentan los periodistas en los tiempos contemporáneos y frente a ello es preciso que la práctica del Periodismo adquiera nuevos valores y perspectivas, sobre todo en un contexto donde el número de visitas recibidas es más importante que la calidad de las noticias publicadas gracias a redes de publicidad digital como Audience Network, Taboola, OpenX o SunMedia, en las que prima la audiencia en términos numéricos.

En esta lucha contra las informaciones falsas y su viralización se hace indispensable, por una parte, que los medios consoliden su credibilidad frente al público, que recuperen su confianza, y por otro, que frente a los beneficios de una comunicación low cost en búsqueda constante de la novedad, se apueste por un periodismo sosegado, de verificación y profundización de los temas.

La credibilidad de los medios es el mayor desafío de los periodistas. Verificar las noticias, destacando lo relevante y rechazando lo que no lo es; así como tamizar los rumores y las insinuaciones son algunos de los retos a los que tiene que hacer frente la profesión periodística y, en este sentido The Trust Project funciona como un indicador de veracidad ya que permite saber quién ha publicado un artículo, qué citas y referencias incorpora y cuáles son los estándares éticos en los que se sustenta.

En los últimos años hemos asistido a un importante crecimiento del fact-checking de la información, y para ello se han diseñado herramientas que evalúan la calidad de la misma, de igual forma, han surgido iniciativas periodísticas encaminadas a la verificación y se ha creado un protocolo de transparencia que garantiza los estándares de calidad de las noticias publicadas. Este es el caso de Maldito bulo, B de Bulo o Newtral, nacidas a consecuencia de la fragmentación existente en el panorama 
mediático y cuya misión es aclarar y arrojar luz a todas las informaciones construidas de forma no adecuada o falsa en los medios de comunicación de España.

No obstante, el esfuerzo realizado por los profesionales de la información debe ir acompasado de la colaboración ciudadana. El receptor es un pilar indispensable en la lucha contra las noticias falsas, y para ello es necesario facilitarle la adquisición de las competencias mediáticas que les permita acceder, comprender, analizar, evaluar y distinguir entre las informaciones reales y las falsas. En este sentido, es preciso apostar por una alfabetización mediática (Fernández-García, 2017) que permita a los receptores luchar contra la creciente tolerancia al engaño y la mentira.

\section{Referencias}

Alonso, M. y García Orta, MJ. (2015). Noticias falsas en Internet: difusión viral a través de las redes sociales. En Livro de Atas do IV COBCIBER. Oporto: Observatório de Ciberjornalismo.

Alonso, P. (2017). Fake news y posverdad en tiempos de populismos: lecciones para periodistas. Cuadernos de periodistas: revista de la Asociación de la Prensa de Madrid, 34, 77-84.

Bravo, G. (2014). Un periódico satírico online deja en evidencia a la 'prensa seria'. Recuperado de https://bit.ly/2FJMuh9

Bossetta, M. (2018). The digital architectures of social media: Comparing political campaigning on Facebook, Twitter, Instagram, and Snapchat in the 2016 US election. Journalism \& mass communication quarterly, 95 (2), 471-496. https://bit.ly/2DuAQ7J

Buldú, J. (2011). La estructura de las Redes Sociales. Recuperado de https://bit.ly/2RamBbE

Casero Ripollés, A. (2018). Investigación sobre información política y redes sociales: puntos clave y retos de futuro. El profesional de la información, 27 (5), 964-974. https://bit.ly/2sF7AVF

Castells, M. (2009). Comunicación y poder. Madrid: Alianza.

ComScore (2018). comScore MMx Multiplataforma de julio. Recuperado de https://bit.ly/2S8sUho

Cremades, J. (2007). Micropoder: La fuerza del ciudadano en la era digital. Madrid: EspasaCalpe.

El Mundo (2018). WhatsApp, nuevo caldo de cultivo para las 'fake news'. Recuperado de https://bit.ly/2R8ZG0q

El Plural (2019). Nuevo proyecto de 'Newtral': la verificación en Facebook. Recuperado de https://bit.ly/2Dtd8sb

Ámbitos. Revista Internacional de Comunicación | ISSN: 1139-1979 | E-ISSN: 1988-5733, №. 45. (2019) 
Fernandez, J. (2018). El País contra Digital Sevilla, Goliat se cabrea tela con David. Recuperado de https://bit.ly/2GMLozh

Fernández, M.A. (2014). La expansión del rumor en los medios digitales. En F. Sabés, F. y J.J. Verón (Eds.), Universidad, Investigación y Periodismo digital (pp.19-36). Aragón: Asociación de Periodistas de Aragón.

Fernández-García, N. (2017). Fake news: una oportunidad para la alfabetización mediática. Nueva Sociedad, 269. Disponible en https://bit.ly/2MpoOPV

Gartner (2017). Predicciones Tecnológicas para el 2018. Recuperado de https://gtnr.it/2ljsDMv

Gil, I. (2018). Francia: Bulos, redes sociales y chalecos amarillos. Recuperado de https://bit.ly/2FUkMOf

Guisado, P. (2018). El falso control de drogas de Albert Rivera: así se gesta un bulo a partir de un hecho. Recuperado de https://bit.ly/2010Nfd

Gutiérrez-Rubi, A. (2015). La política en tiempos de WhatsApp. Madrid: El País.

Jané, C. (2017). La mitad de las noticias que circulen en 2022 serán falsas. Recuperado de https://bit.ly/2yKsjN1

Jané, C. (2018). EI MIT descubre cómo detectar de forma automática las noticias falsas. Recuperado de https://bit.ly/2U9HqGf

Journell, W. (2017). Fake news, alternative facts, and Trump: Teaching social studies in a posttruth era. Social Studies Journal, 37 (1), 8-21.

Kawulich, B. (2005). Participant Observation as a Data Collection Method. Forum Qualitative Sozialforschung, 6 (2), Art. 43. https://bit.ly/1wkx7hM

Keane, J. (2013). Democracy and media decadence. Cambridge: Cambridge University Press.

Knight Foundation (2018). Seven ways misinformation spread during the 2016 election. https://bit.ly/2QuVTur

Kovach, B. y Rosentiel, T. (2003). Los elementos del Periodismo. Madrid: El País.

López-Borrull, A; Vives-Gràcia, J.; Badell, Jl. (2018). Fake news, ¿amenaza u oportunidad para los profesionales de la información y la documentación? El profesional de la información, 27 (6), 1346-1356. https://bit.ly/2T4nVyC

Martínez, M. (2018). 'Fake news' en México: cómo un mensaje de WhatsApp llevó a un pequeño pueblo a quemar vivos a dos hombres inocentes. Recuperado de https://bbc.in/2Fjogln

McIntyre, L. (2018). Postverdad. Madrid: Cátedra. 
Monfort, J (2018). Twitter y el problema de las 'fake news': se publican más de un millón al día en la plataforma. https://bit.ly/2R7RLRd

Nahon, K. (2016). Where there is social media there is politics. En A. Bruns, G. Enli, E. Skogerbö, A. Larsson, C, Christensen (Eds.), Routledge companion to social media and politics (pp.39-55). New York: Routledge.

Newman, N. (2018). Trust, misinformation, and decling use of social media for news: Digital News Report 2018. Disponible en https://bit.ly/2MtbFnQ

Owen, D. (2018). El papel de los nuevos medios en la política. En AAVV (2018), La era de la perplejidad. Madrid: Taurus. Recuperado de https://bit.ly/2O95FSM

Peinado, F. y Muela, D. (2018). El negocio de la manipulación digital en España. Recuperado de https://bit.ly/2Gz2P6o

Pew Research Center (2018). Social media outpaces print newspapers in the U.S. as a news source. Recuperado de https://pewrsr.ch/2UvWPSe

Rochlin, N. (2017). Fake news: Belief in post-truth. Library hi Tech, 35 (3), 386-392. https://bit.ly/2DLvToM

Sedano, J. (2018). Las webs para crear noticias falsas detrás de gran parte de los bulos que circulan por WhatsApp y redes sociales. Recuperado de https://bit.ly/2MvWI5C

Stier, S.; Bleier, A.; Lietz, H. y Strohmaier, M. (2018). Election campaigning on social media: Politicians, audiences, and the mediation of political communication on Facebook and Twitter". Political communication, 35 (1), 50-74. https://bit.ly/2FResqy

Sunstein, C. (2009). On rumours. How Falsehoods Spread, Why We Believe Them, What Can Be Done. Londres: Penguin.

Tardaguila, C. (2018). Desinformación 'inteligente' marcó la pauta en 2018. Recuperado de https://bit.ly/2HpO1ur

Torres, R. (2007). La verificación brilla por su ausencia en la red. Periodistas: Revista de la Federación de Asociaciones de Periodistas de España, 11, 35-37.

Torres, M. y Lorenzo, A. (2018). Fake News: cifras y soluciones de un fenómeno global. Recuperado de https://bbva.info/2TEjv1s

Van-Aelst, P.; Strömbäck, J.; Aalberg, T.; Esser, F.; De-Vreese, C.; Matthes, J.; Hopmann, D.; Salgado, S.; Hubé, N.; Stępińska, A.; Papathanassopoulos, S.; Berganza, R.; Legnan, G.; Reinemann, C.; Sheafer, T. y Stanyer, J. (2017). Political communication in a highchoice media environment: a challenge for democracy? Annals of the International Communication Association, 41 (1), 3-27. https://bit.ly/2TazhRB

Van-Dijck, J. (2009). Users like you? Theorizing agency in user-generated content. Media, culture \& society, 31 (1), 41-58. https://bit.ly/2FU97Ph 
Vosoughi, S.; Roy, D.; y Aral, S. (2018). The spread of true and false news online. Science, 359, 1146-1151.

Wardle, C. (2018). Information Disorder. Part 3: Useful Graphics. Recuperado de https://bit.ly/2wjjRAx

Ámbitos. Revista Internacional de Comunicación | ISSN: 1139-1979 | E-ISSN: 1988-5733, №. 45. (2019) 